\title{
After neoadjuvant chemoradiation therapy, predicted pulmonary function may be reduced by $10 \%$
}

\author{
Benny Weksler, MD, MBA
}

\author{
From the Division of Thoracic Surgery, University of Tennessee Health Science Center, Memphis, Tenn. \\ Disclosures: B.W. is a Proctor for Intuitive Surgery. \\ Received for publication Dec 31, 2017; accepted for publication Jan 10, 2018; available ahead of print Feb 23, \\ 2018. \\ Address for reprints: Benny Weksler, MD, MBA, Division of Thoracic Surgery, University of Tennessee Health \\ Science Center, 1325 Eastmoreland Ave, Suite 460, Memphis, TN 38104 (E-mail: bweksler@uthsc.edu). \\ J Thorac Cardiovasc Surg 2018;155:2127-8 \\ $0022-5223 / \$ 36.00$ \\ Copyright (C) 2018 by The American Association for Thoracic Surgery \\ https://doi.org/10.1016/j.jtcvs.2018.01.024
}

The use of preoperative chemoradiation therapy in patients with locally advanced lung cancer has become widespread. Despite evidence that the addition of surgery to definitive chemoradiation does not improve overall survival in patients with mediastinal disease, ${ }^{1}$ patients with an excellent response to therapy occasionally are deemed surgical candidates. The use of preoperative chemoradiation has been shown to decrease pulmonary function, but the exact cause of the decrease is unknown. ${ }^{2,3}$

In the current issue of the Journal, Nomori and colleagues ${ }^{4}$ report detailed changes in pulmonary function after preoperative chemoradiation therapy. The authors' institution uses preoperative chemoradiation for patients with tumors classified as T3 or T4, for patients with $\mathrm{N} 2$ disease, and for patients with N1 disease invading the bronchus. With the use of spirometry and single-photon emission computed tomography, the authors measured lung function before and after lobectomy in patients who received preoperative chemoradiation and patients who did not and compared lung function between the 2 treatment groups. Single-photon emission computed tomography is a sensitive method to determine regional lung perfusion and was used to predict postoperative lung function. The treatment groups were propensity matched for the location of the tumor and other relevant variables. As shown in previous studies, preoperative chemoradiation therapy decreased lung function postoperatively. Of note, the loss of lung function was due to decreased function in the remaining ipsilateral lobes, while contralateral lung function actually improved. The difference in lung function between the groups was approximately $10 \%$ (77\% in patients with preoperative chemoradiation vs $86 \%$ in patients with surgery alone), and all of the difference could be attributed to a decrease in function of the remaining ipsilateral lobes, despite an increase in function of approximately $5 \%$ in the contralateral lung.

An important clinical implication of Nomori and colleagues' work ${ }^{4}$ is the need to recognize that predicting postoperative pulmonary function using standard formulas will

\section{References}

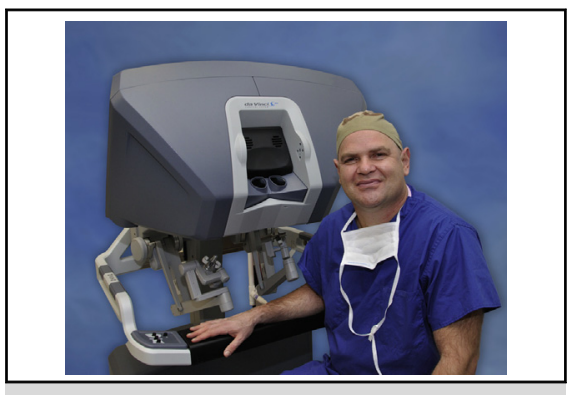

Benny Weksler, MD, MBA

Central Message

After neoadjuvant chemoradiation therapy, predicted postoperative pulmonary function overestimates actual function by $10 \%$, which has implications for patients with borderline preoperative function.

See Article page 2129.

overestimate the patient's actual lung function by $10 \%$ or so after neoadjuvant chemoradiation. So, patients with a predicted postoperative forced expiratory volume in 1 second of $40 \%$ of predicted will actually have $30 \%$ of predicted. The potential consequences for patients with borderline lung function are clear.

However, it is important to note that the findings of the PACIFIC trial, which demonstrated significant improvement in progression-free survival when the monoclonal antibody durvalumab was administered as consolidation therapy after chemoradiation, have been changing the way practitioners treat patients with IIIA and IIIB lung cancer. ${ }^{5}$ The resulting changes may affect a significant portion of the patients included in Nomori and colleagues' study ${ }^{4}$ (eg, all patients with $\mathrm{N} 2$ disease and patients with T4N0-N1 lung cancer). In addition, the current National Comprehensive Cancer Network ${ }^{6}$ guidelines do not recommend neoadjuvant therapy for patients with $\mathrm{N} 1$ disease, a subset included in Nomori and colleagues' study. The National Comprehensive Cancer Network has incorporated the PACIFIC trial findings into its latest guidelines, and it is likely that the majority of patients with IIIA disease will receive definitive chemoradiation followed by consolidation therapy with durvalumab rather than surgery.

1. Albain KS, Swann RS, Rusch VW, Turrisi AT III, Shepherd FA, Smith C, et al Radiotherapy plus chemotherapy with or without surgical resection for stage III 
non-small-cell lung cancer: a phase III randomised controlled trial. Lancet. 2009; 374:379-86.

2. Cerfolio RJ, Talati A, Bryant AS. Changes in pulmonary function tests after neoadjuvant therapy predict postoperative complications. Ann Thorac Surg. 2009;88: 930-6.

3. Margaritora S, Cesario A, Cusumano G, Cafarotti S, Corbo GM, Ferri L, et al. Is pulmonary function damaged by neoadjuvant lung cancer therapy? A comprehensive serial time-trend analysis of pulmonary function after induction radiochemotherapy plus surgery. J Thorac Cardiovasc Surg. 2010;139:1457-63.
4. Nomori H, Shiraishi A, Cong Y, Shoji K, Misawa M, Sugimura H, et al. Impact of induction chemoradiotherapy on pulmonary function after lobectomy for lung cancer. J Thorac Cardiovasc Surg. 2018;155:2129-37.e1.

5. Antonia SJ, Villegas A, Daniel D, Vicente D, Murakami S, Hui R, et al. Durvalumab after chemoradiotherapy in Stage III non-small-cell lung cancer. $N$ Engl J Med. 2017;377:1919-29.

6. Ettinger DS, Wood DE, Aisner DL, Akerley W, Bauman J, Chirieac LR, et al. NonSmall Cell Lung Cancer, Version 5.2017, NCCN Clinical Practice Guidelines in Oncology. J Natl Compr Canc Netw. 2017;15:504-35. 